\title{
Anatomia comparada do pulvino primário de leguminosas com diferentes velocidades de movimento foliar ${ }^{1}$
}

\author{
TATIANE MARIA RODRIGUES ${ }^{2,3}$ e SILVIA RODRIGUES MACHADO ${ }^{2}$
}

(recebido: 9 de fevereiro de 2006; aceito: 23 de novembro de 2006)

\begin{abstract}
Primary pulvinus comparative anatomy of leguminous species with different leaf movement velocity). The pulvinus, structure responsible for slow or fast leaf movements answering to outside or endogenous stimulus, constitutes a remarkable feature of leguminous species. The leaf position adjustments represent an efficient mechanism that allows the photosynthesis maximization under adverse conditions. In the available literature, the majority of the information about pulvinus structure refers to few leguminous species, especially those with fast movements. In this work the primary pulvinus anatomy of nine leguminous species from Brazilian "cerrado" with different kinds and velocity of leaf movement is described, attempting to identify patterns and to point structural peculiarities. The primary pulvinus of the studied species show uniseriate epidermis recovered by thick cuticle, large parenchymatous cortex, central vascular system and reduced or absent pith. The outer cortex cells are wider and show phenolic compounds, except in Zornia diphylla Pers.; in the inner cortex, the cells are juxtaposed and do not have phenolic content. The collateral vascular bundles are surrounding by a septate fibers sheath. The general anatomy organization pattern is common to the pulvini of the studied species, independently of the subfamily they belong. The observed peculiarities are possible related to the kind and velocity of leaf movement.
\end{abstract}

Key words - anatomy, Fabaceae, leaf movement, pulvinus

RESUMO - (Anatomia comparada do pulvino primário de leguminosas com diferentes velocidades de movimento foliar). Os pulvinos, estruturas responsáveis por movimentos foliares, rápidos ou lentos, em resposta a estímulos externos ou endógenos, constituem uma característica marcante das leguminosas. Os ajustes no posicionamento foliar representam um mecanismo eficiente que permite a maximização da fotossíntese em condições adversas. Na literatura disponível, a maioria das informações sobre a estrutura de pulvinos refere-se a poucas espécies de leguminosas, especialmente aquelas que apresentam movimentos rápidos. Neste trabalho é descrita a anatomia do pulvino primário de nove espécies de leguminosas nativas do cerrado com diferentes tipos e velocidades de movimento foliar, buscando identificar padrões e apontar peculiaridades estruturais. O pulvino primário das espécies estudadas apresenta epiderme unisseriada recoberta por cutícula espessa, córtex parenquimático amplo, sistema vascular central e medula reduzida ou ausente. As células do córtex externo são maiores e apresentam conteúdo fenólico, exceto em Zornia diphylla Pers.; no córtex interno, as células são justapostas e não possuem conteúdo fenólico. Os feixes vasculares colaterais são circundados por uma bainha de fibras septadas. O padrão geral de organização anatômica é comum ao pulvino das espécies estudadas, independentemente da subfamília a qual pertencem. As peculiaridades observadas estão possivelmente relacionadas com o tipo e velocidade do movimento foliar.

Palavras-chave - anatomia, Fabaceae, movimento foliar, pulvino

\section{Introdução}

Fabaceae (= Leguminosae), pertencente à ordem Fabales, é uma das maiores famílias de angiospermas, com cerca de 650 gêneros e 18.000 espécies (Polhill 1981, Judd et al. 1999, Souza \& Lorenzi 2005), sendo que no Brasil ocorrem cerca de 200 gêneros e 1.500 espécies. Possui distribuição cosmopolita com espécies

\footnotetext{
1. Parte da dissertação da primeira autora, Programa de Pós-Graduação em Ciências Biológicas/Botânica da Universidade Estadual Paulista, Câmpus de Botucatu.

2. Universidade Estadual Paulista, Instituto de Biociências, Departamento de Botânica, Câmpus de Botucatu, Caixa Postal 510, 18618-000 Botucatu, SP, Brasil.

3. Autor para correspondência: tatiane@ibb.unesp.br
}

herbáceas, arbustivas, arbóreas e lianas, além de ser uma das principais famílias do ponto de vista econômico (Souza \& Lorenzi 2005). Segundo Souza \& Lorenzi (2005), as leguminosas estão bem representadas na maioria dos ecossistemas naturais brasileiros. No cerrado, é a família mais representativa em número de espécies, com cerca de 777 distribuídas em aproximadamente 101 gêneros (Ratter et al. 1997, Mendonça et al. 1998).

Uma das principais características que distinguem Fabaceae das demais famílias da ordem Fabales é a ocorrência de folhas compostas com pulvinos bem evidentes (Judd et al. 1999). Os pulvinos, espessamento da base foliar, são responsáveis pelos movimentos foliares, rápidos ou lentos, em resposta a estímulos externos ou endógenos (Campbell \& Thomson 1977, 
Campbell et al. 1979, Satter et al. 1982, Moysset \& Simón 1991, Grignon et al. 1992).

Os mecanismos fisiológicos responsáveis pelos movimentos foliares em algumas espécies de leguminosas têm sido correlacionados com as características estruturais do pulvino, que lhes conferem grande flexibilidade. Entre as características comumente reportadas, destacam-se córtex amplo constituído por células parenquimáticas, denominadas células motoras por Toriyama (1953), sistema vascular em posição central, ausência ou redução de tecidos lignificados e medula reduzida ou ausente. Entretanto, de maneira geral, a maior parte dessas informações refere-se ao pulvino de poucas espécies de Mimosoideae, tais como Samanea saman (Jacq.) Merr. (Satter et al. 1982), Robinia pseudoacacia L. (Moysset \& Simón 1991), Albizzia julibrissin Durass. (Satter et al. 1970, Campbell \& Garber 1980) e Mimosa pudica L., sendo esta a mais estudada e caracterizada por movimentos foliares rápidos (Toriyama 1953, 1954, 1955, 1957, 1967, Toriyama \& Satô 1968, Toriyama \& Komada 1971, Campbell \& Thomson 1977, Fleurat-Lessard \& Bonnemain 1978, Campbell et al. 1979, Fleurat-Lessard 1981, 1988, Fleurat-Lessard \& Roblin 1982, FleuratLessard \& Millet 1984).

No cerrado, onde as plantas estão sujeitas às limitações impostas pela alta radiação, temperaturas elevadas e períodos de seca bem delimitados, o ajuste foliar torna-se um importante mecanismo de adaptação às condições do ambiente relacionada com economia de água e maximização da fotossíntese (Caldas et al. 1997). Contudo, para as leguminosas nativas de cerrado, as informações sobre a estrutura e funcionamento de pulvinos são escassas e restritas à Pterodon pubescens, uma leguminosa arbórea com movimentos foliares lentos (Caldas et al. 1997, Machado \& Rodrigues 2004, Rodrigues \& Machado 2004). Não existem estudos estruturais do pulvino de um número representativo de espécies da família Fabaceae com diferentes tipos e velocidades de movimento, visando analisar peculiaridades estruturais relatadas em literatura.

Neste trabalho é descrita a anatomia do pulvino primário de nove espécies de leguminosas nativas do cerrado com diferentes tipos e velocidades de movimento foliar, buscando identificar padrões e apontar peculiaridades estruturais.

\section{Material e métodos}

Foram estudadas nove espécies de leguminosas com diferentes tipos de movimentos foliares, distribuídas nas subfamílias Caesalpinoideae, Faboideae e Mimosoideae (tabela 1), segundo classificação de Polhill (1981). Nesse estudo foi adotado o conceito de pulvino primário empregado por Fleurat-Lessard (1981) para o espessamento localizado na base do pecíolo, ligando a folha ao caule. Amostras da região mediana do pulvino primário foram retiradas de folhas completamente expandidas, coletadas de exemplares vegetando em cerrado no Município de Pratânia-SP

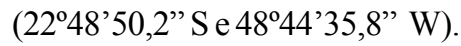

As amostras foram fixadas em FAA com etanol $50 \%$ por 48 horas (Johansen 1940). A seguir, parte foi desidratada em série etílica, incluída em resina metacrilato e seccionada em micrótomo de rotação semi-automático; os cortes, com $6 \mu \mathrm{m}$ a $8 \mu \mathrm{m}$ de espessura, foram corados com azul de toluidina 0,05\%, pH 4,7 (O'Brien et al. 1965) e montados entre lâmina e lamínula com Permount. Outra parte das amostras foi estocada

Tabela 1. Espécies estudadas e tipo de movimento foliar.

Table 1. Studied species and kind of leaf movement.

\begin{tabular}{|c|c|c|}
\hline Sub família & Espécie & Movimento foliar \\
\hline Caesalpinioideae & $\begin{array}{l}\text { Bauhinia rufa (Bong.) Steud. } \\
\text { Copaifera langsdorffii Desf. } \\
\text { Senna rugosa (G. Don.) H.S. Irwin \& Barneby }\end{array}$ & $\begin{array}{l}\text { heliotrópico e nictinástico lentos } \\
\text { heliotrópico e nictinástico lentos } \\
\text { heliotrópico e nictinástico lentos }\end{array}$ \\
\hline Faboideae & $\begin{array}{l}\text { Andira humilis Mart. ex Benth. } \\
\text { Dalbergia miscolobium Benth. } \\
\text { Zornia diphylla Pers. }\end{array}$ & $\begin{array}{l}\text { heliotrópico e nictinástico lentos } \\
\text { heliotrópico e nictinástico lentos } \\
\text { heliotrópico lento }\end{array}$ \\
\hline Mimosoideae & $\begin{array}{l}\text { Mimosa rixosa Mart. } \\
\text { Mimosa flexuosa Mart. } \\
\text { Stryphnodendron polyphyllum Mart. }\end{array}$ & $\begin{array}{l}\text { heliotrópico e nictinástico lentos; } \\
\text { seismonástico rápido } \\
\text { heliotrópico e nictinástico lentos; } \\
\text { seismonástico rápido } \\
\text { heliotrópico e nictinástico lentos }\end{array}$ \\
\hline
\end{tabular}


em álcool etílico 70\%, e posteriormente seccionada à mãolivre com auxílio de lâminas de barbear ou com micrótomo de Ranvier; os cortes foram clarificados em hipoclorito de sódio a 20\%, lavados em água acética 1\%, corados com azul de astra e safranina (Bukatsch 1972, Burger \& Richter 1991) e montados entre lâmina e lamínula com glicerina. Secções de material recém coletado, não fixado, foram tratadas com Sudan IV para detecção de substâncias lipídicas (Johansen 1940); solução de vermelho de rutênio a $0,02 \%$ para substâncias pécticas (Jensen 1962); reagente de lugol para amido (Johansen 1940); solução de cloreto férrico a $10 \%$ para substâncias fenólicas (Johansen 1940); floroglucinol acidificado para lignina (Sass 1951) e ácido clorídrico a 10\% para cristais de oxalato de cálcio (Johansen 1940). Os aspectos relevantes foram fotografados em fotomicroscópio Zeiss ${ }^{\circledR}$, utilizando filme $\operatorname{Kodak}^{\circledR}$ Asa 100 e T-Max Asa 100.

O comprimento e o diâmetro do pulvino $(n=10)$ de cada espécie foram mensurados com auxílio de paquímetro digital.

\section{Resultados}

Os pulvinos primários das nove espécies estudadas apresentam dimensões morfológicas bastante variáveis (tabela 2).

Em secção transversal (figuras 1-9), apresentam formato circular (figuras 1, 3, 5, 7, 9) ou discretamente dorsi-ventral (figuras 2, 4, 6, 8). A superfície dos pulvinos pode ser regular (figuras 3, 5, 7, 9) ou apresentar ondulações (figuras 1, 2, 4, 6, 8). Em todas as espécies os pulvinos primários apresentam epiderme unisseriada, córtex parenquimático amplo, sistema vascular central e medula bastante reduzida (figuras 1-6, 9) ou ausente (figuras 7-8).

Tricomas tectores ocorrem na superfície do pulvino de Copaifera langsdorffii Desf. (figura 2), Dalbergia miscolobium Benth., Zornia diphylla Pers. e Mimosa flexuosa Mart., sendo mais abundantes em Bauhinia rufa (Bong.) Steud. (figuras 1, 11) e Senna rugosa (G. Don.) H. S. Irwin \& Barneby; nas demais espécies, não foram observados tricomas. Cutícula espessa lisa recobre as células epidérmicas dos pulvinos de Bauhinia rufa (figura 11), Copaifera langsdorffii (figura 13), Senna rugosa, Andira humilis Mart. ex Benth. (figuras 15, 17), Dalbergia miscolobium e Stryphnodendron polyphyllum Mart. Em Zornia diphylla (figura 14), Mimosa rixosa Mart. e Mimosa flexuosa, a cutícula é menos espessada.

Em Mimosa flexuosa (figura 10), são observadas protuberâncias formadas pela epiderme e cerca de seis camadas de células justapostas com paredes espessas e lignificadas em toda a superfície do pulvino primário (figura 8).

A epiderme é formada por células papiliformes em Bauhinia rufa (figura 11), Senna rugosa e Dalbergia miscolobium. Em Zornia diphylla (figura 14), Mimosa rixosa, Mimosa flexuosa e Stryphnodendron polyphyllum, Copaifera langsdorffii (figura 13) e Andira humilis (figura 17) as células epidérmicas apresentam forma retangular. Em Dalbergia miscolobium e nas espécies de Caesalpinioideae (figuras 11-13) e de Mimosoideae foi detectada a presença de conteúdo fenólico nos vacúolos das células epidérmicas. Estômatos não foram observados em nenhuma das espécies.

O córtex do pulvino (figuras 1-9, 15) é amplo, variando de 20 a 30 camadas de células parenquimáticas, com exceção de Zornia diphylla (figura 6) onde é mais reduzido, com cerca de 15 camadas. As células corticais apresentam tamanho e formato variáveis, paredes pecto-

Tabela 2. Dados médios do comprimento e diâmetro do pulvino primário das espécies estudadas.

Table 2. Avarage data about primary pulvinus lenght and diameter of the studied species.

\begin{tabular}{|c|c|c|c|}
\hline \multirow[t]{2}{*}{ Espécie } & \multirow[t]{2}{*}{ Porte } & \multicolumn{2}{|c|}{ Pulvino } \\
\hline & & $\begin{array}{l}\text { Comprimento } \\
\text { (mm) }\end{array}$ & $\begin{array}{c}\text { Diâmetro } \\
\text { (mm) }\end{array}$ \\
\hline Bauhinia rufa (Bong.) Steud. & arbustivo & 3,98 & 2,99 \\
\hline Copaifera langsdorffii Desf. & arbóreo & 1,91 & 1,83 \\
\hline Senna rugosa (G. Don.) H. S. Irwin \& Barneby & arbustivo & 3,95 & 3,08 \\
\hline Andira humilis Mart. ex Benth. & arbustivo & 4,21 & 3,00 \\
\hline Dalbergia miscolobium Benth. & arbóreo & 4,48 & 4,36 \\
\hline Zornia diphylla Pers. & herbáceo & 2,10 & 1,14 \\
\hline Mimosa rixosa Mart. & rasteiro & 2,08 & 1,20 \\
\hline Mimosa flexuosa Mart. & herbáceo & 1,60 & 1,00 \\
\hline Stryphnodendron polyphyllum Mart. & arbóreo & 4,24 & 3,15 \\
\hline
\end{tabular}



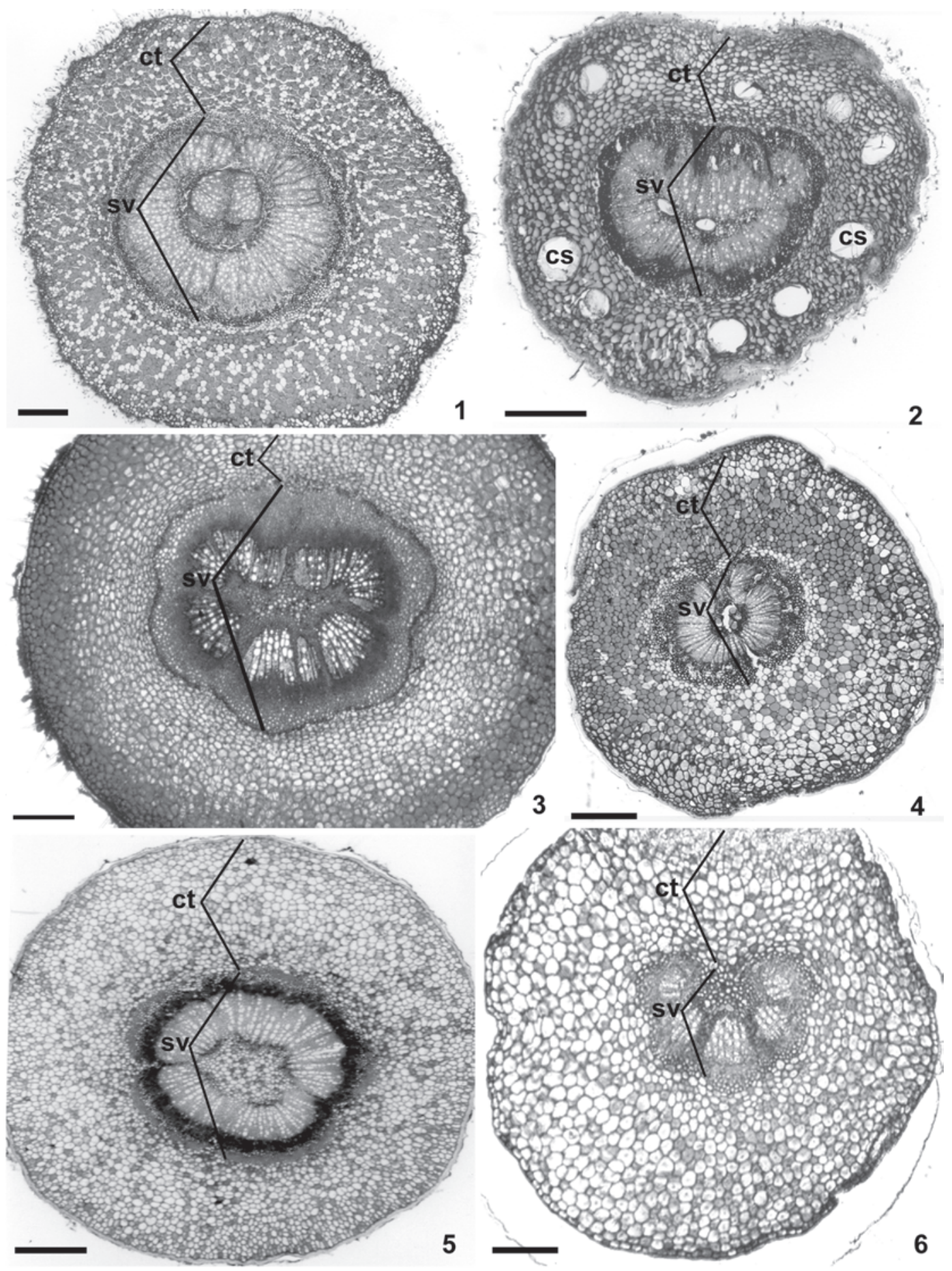

Figuras 1-6. Secções transversais do pulvino de leguminosas do cerrado. 1-6. Aspecto geral mostrando epiderme unisseriada, córtex parenquimático amplo, sistema vascular central e medula reduzida. Observar o conteúdo denso (substâncias fenólicas) nas células corticais nas figuras 1-5. 1. Bauhinia rufa (Bong.) Steud. 2. Copaifera langsdorffii Desf. 3. Senna rugosa (G. Don.) H. S. Irwin \& Barneby. 4. Andira humilis Mart. ex Benth. 5. Dalbergia miscolobium Benth. 6. Zornia diphylla Pers. (cs = cavidade secretora; ct = córtex; sv = sistema vascular). Barras $=350 \mu \mathrm{m}(1-5), 180 \mu \mathrm{m}(6)$.

Figures 1-6. Pulvinus of legumes from Brazilian "cerrado" transversal sections. 1-6. General view showing uniseriate epidermis, large parenchymatous cortex, central vascular system and reduced pith: observe the dense content (phenolic compounds) of the cortical cells in the figures 1-5. 1. Bauhinia rufa (Bong.) Steud. 2. Copaifera langsdorffii Desf. 3. Senna rugosa (G. Don.) H. S. Irwin \& Barneby. 4. Andira humilis Mart. ex Benth. 5. Dalbergia miscolobium. 6. Zornia diphylla. (cs = secretory cavity; $\mathrm{ct}=\mathrm{có} r \mathrm{tex} ; \mathrm{sv}=$ vascular system). Bars $=350 \mu \mathrm{m}(1-5), 180 \mu \mathrm{m}(6)$. 
celulósicas delgadas (figuras 10-17) com campos de pontoação perceptíveis (figura 16), além de núcleo proeminente (figuras 12, 14, 16). De acordo com o tamanho e a disposição das células e o conteúdo celular, distinguem-se no córtex a região cortical externa e a região cortical interna (figura 15).

$\mathrm{Na}$ região cortical externa, as células parenquimáticas são mais volumosas (figura 15), apresentam núcleo (figuras 12,14,16) e vacuoma conspícuos (figuras 10-12, 15). Possuem forma poliédrica e paredes delgadas sinuosas (figura 14) com campos de pontoação conspícuos (figura 16). Espaços intercelulares são comuns nesta região (figura 10). A maioria das células do córtex externo apresenta vacúolo com substâncias fenólicas (figuras 11-12, 15) que se coram de verde intenso com o azul de toluidina, exceto em Zornia diphylla (figuras 6, 14, 16). Em Bauhinia rufa (figuras 1, 11-12), Copaifera langsdorffii (figura 2), Dalbergia miscolobium (figura 5), Mimosa rixosa (figura 7) e Mimosa flexuosa (figura 8) o conteúdo fenólico mostrou-se mais abundante, evidenciado com a coloração pelo azul de toluidina e pelo teste com o cloreto férrico. Cristais de oxalato de cálcio na forma de drusas também foram observados em algumas células do córtex externo de Bauhinia rufa (figura 12); em Copaifera langsdorffii (figura 13), Mimosa rixosa e Stryphnodendron polyphyllum (figura 9) ocorrem cristais prismáticos. Em Andira humilis esclereídes esparsas foram observadas na região cortical externa (figura 17). Espaços secretores delimitados por epitélio unisseriado foram observados em Copaifera langsdorffii (figuras 2, 13); em corte longitudinal, tais espaços apresentam-se alongados, o que os caracteriza como canais secretores. Divisões periclinais e anticlinais foram observadas nas camadas celulares subepidérmicas em Bauhinia rufa (figura 12), Senna rugosa, Andira humilis, Dalbergia miscolobium, Mimosa rixosa, Mimosa flexuosa e Stryphnodendron polyphyllum.

A região cortical interna dos pulvinos é formada por cerca de três ou quatro camadas de células parenquimáticas que se caracterizam pelo tamanho menor, disposição compacta e ausência de conteúdo fenólico (figuras 15, 18-20). Esta região não possui espaços intercelulares. A camada cortical mais interna é constituída por células repletas de grãos de amido (figuras 18-19). As camadas corticais adjacentes à interna também podem apresentar grãos de amido esparsos. Em Bauhinia rufa (figura 19), Copaifera langsdorffii, Senna rugosa, Andira humilis (figura 23), Dalbergia miscolobium e Stryphnodendron polyphyllum além de grãos de amido, as células da camada cortical mais interna apresentam cristais prismáticos de oxalato de cálcio.

O sistema vascular se localiza centralmente (figuras 1-9); os feixes vasculares podem se apresentar organizados em um anel (figuras 1-3, 5, 7-9) ou em ferradura (figuras 4, 6); externamente são delimitados por um número variável de camadas de células pequenas com paredes pecto-celulósicas espessadas (figuras 1-9, 20). Em secção longitudinal (figura 23), essas células são fusiformes, apresentam vários septos, além de campos de pontoação conspícuos, o que as caracteriza como fibras septadas.

O floema é constituído por elementos de tubo crivado, células companheiras e células de parênquima axial, além de células de parênquima radial (figuras 20, 22). Em Bauhinia rufa, Copaifera langsdorffii, Andira humilis (figura 20), Dalbergia miscolobium, Mimosa rixosa, Mimosa flexuosa e Stryphnodendron polyphyllum são observados idioblastos fenólicos conspícuos. Idioblastos com cristais prismáticos de oxalato de cálcio foram observados no floema de Bauhinia rufa, Senna rugosa e Andira humilis. Em Mimosa rixosa (figura 22) ocorrem idioblastos com conteúdo mucilaginoso que se cora de rosa intenso com o azul de toluidina.

No xilema, os elementos de vaso são associados às células parenquimáticas axiais e fibras com paredes espessas não-lignificadas. Raios parenquimáticos atravessam o xilema e o floema e atingem a bainha de fibras septadas (figura 20). Nas espécies de Mimosoideae (figuras 7-9), os raios parenquimáticos são pouco nítidos. Em Bauhinia rufa e Andira humilis (figura 20), os mesmos mostram conteúdo fenólico.

A região medular é reduzida (figuras 1-7,9) estando ausente nas espécies de Mimosa (figuras 7-8). É constituída por células parenquimáticas que podem apresentar conteúdo fenólico como em Bauhinia rufa, Senna rugosa, Andira humilis (figura 4), Dalbergia miscolobium e Zornia diphylla (figuras 6, 21).

\section{Discussão}

A organização anatômica dos pulvinos das diferentes espécies estudadas é típica de pulvino de leguminosas, como descrito em literatura (Toriyama 1953, 1954, 1955, 1957, 1967, Toriyama \& Satô 1968, Toriyama \& Komada 1971, Satter et al. 1970, Campbell \& Thomson 1977, Fleurat-Lessard \& Bonnemain 1978, Campbell et al. 1979, Fleurat-Lessard 1981, 1988, Fleurat-Lessard \& Roblin 1982, Fleurat-Lessard \& Millet 1984, Moysset \& Simón 1991, Machado \& 

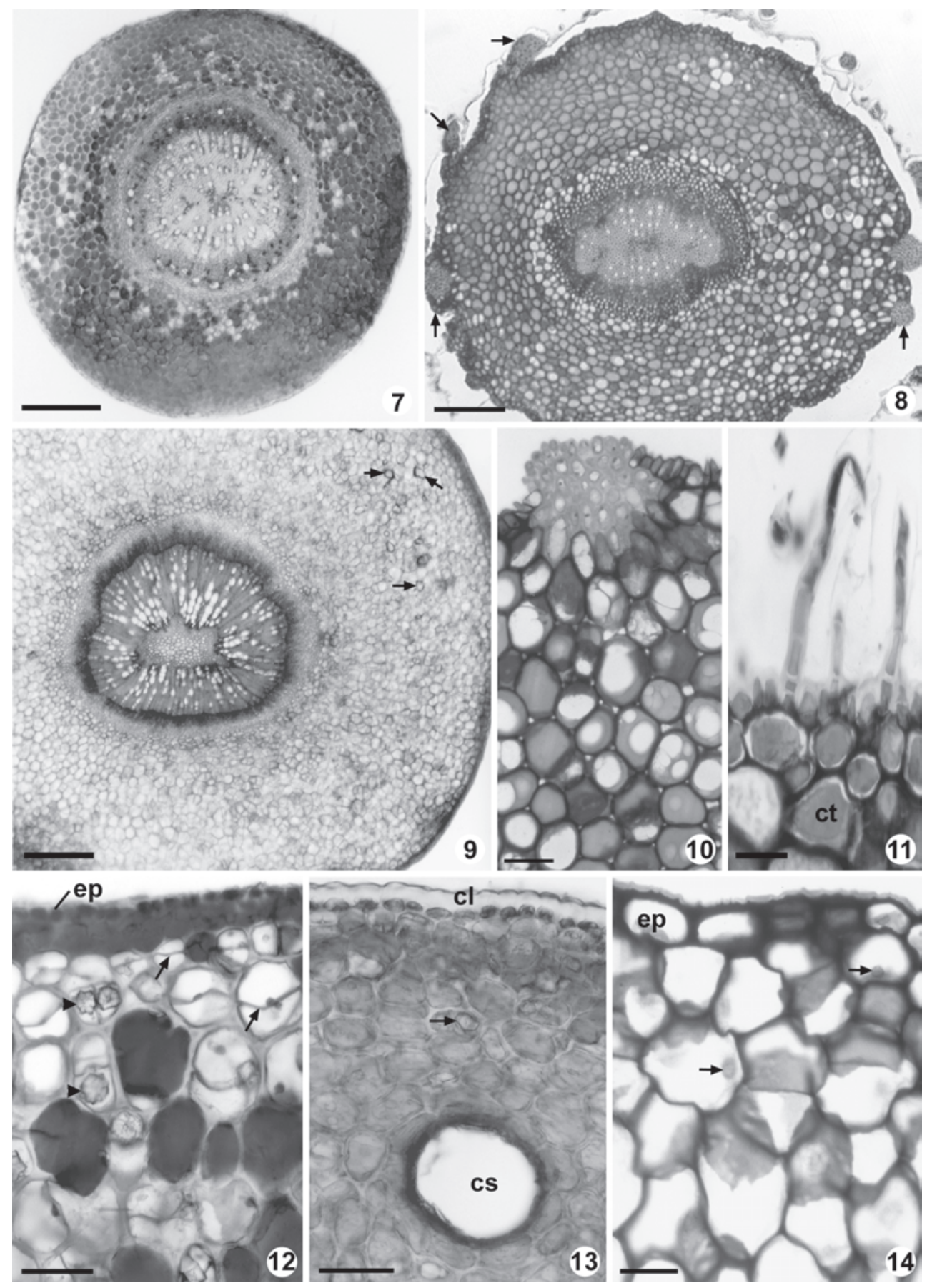

Figuras 7-14. Secções transversais do pulvino de leguminosas do cerrado. 7-9. Aspecto geral mostrando epiderme unisseriada, córtex (ct) parenquimático amplo, sistema vascular (sv) central e medula ausente ou reduzida. 7. Mimosa rixosa Mart. 8. Mimosa flexuosa Mart. - ocorrência de protuberâncias lignificadas (setas) na superfície do pulvino e conteúdo denso (substâncias fenólicas) nas células corticais. 9. Stryphnodendron polyphyllum Mart. - cristais prismáticos de oxalato de cálcio (setas) no córtex. 10. Detalhe da figura 8 destacando protuberância lignificada na superfície do pulvino e vacuoma desenvolvido nas células corticais externas. 11. Bauhinia rufa (Bong.) Steud. - tricomas tectores e epiderme unisseriada formada por células papilosas com cutícula espessa; células epidérmicas e corticais (ct) com conteúdo fenólico. 12. Bauhinia rufa mostrando epiderme (ep) com conteúdo fenólico, células subepidérmicas em divisão periciclinal (setas) e anticlinal e presença de compostos fenólicos e drusas (pontas de seta) nas células corticais. 13. Copaifera langsdorffii Desf. - epiderme de cutícula (cl) espessa, canal secretor (cs) e cristal prismático (seta) no córtex externo. 14. Zornia diphylla Pers. - células epidérmicas (ep) retangulares com cutícula delgada e córtex parenquimático formado por células volumosas com núcleo conspícuo (setas) e ausência de conteúdo fenólico. Barras $=250 \mu \mathrm{m}(7,9), 160 \mu \mathrm{m}(8), 30 \mu \mathrm{m}(10-11,14), 50 \mu \mathrm{m}(12-13)$. 
Rodrigues 2004, Rodrigues \& Machado 2004).

A variação nas dimensões morfológicas dos pulvinos primários, conforme mostrado na tabela 2 , está provavelmente relacionada ao porte da espécie em questão e, principalmente, com o tamanho foliar.

A presença de ondulações na superfície do pulvino é uma das características que o diferencia do pecíolo e raque e está diretamente relacionada com a maior capacidade de movimentação dessa região foliar, como descrito em Mimosa pudica L. (Toriyama 1953). A ocorrência de divisões periclinais e anticlinais na região subepidérmica é comum em pulvinos e está relacionada com a formação de tais protuberâncias (Rodrigues \& Machado 2004).

A ausência de estômatos e a presença de cutícula espessa revestindo a epiderme do pulvino, assim como a ocorrência de tricomas tectores em algumas espécies, pode ter significado importante na defesa contra a perda de água em condições atmosféricas desfavoráveis (Kummerow \& Alexander 1978, Kolattukudy 1984, Larcher 2000). Tais características têm especial significado no cerrado, onde as plantas estão sujeitas a um período de seca prolongado, altas intensidades luminosas e temperaturas elevadas, como referido por Caldas et al. (1997).

A ocorrência de córtex parenquimático amplo é uma das características que diferenciam o pulvino das demais regiões foliares, especialmente do pecíolo e raque (Fleurat-Lessard \& Roblin 1982, Rodrigues \& Machado 2004). As características histológicas gerais do córtex do pulvino primário das nove espécies em estudo são similares às descritas para Mimosa pudica (Toriyama 1953, 1954, Fleurat-Lessard \& Millet 1984, FleuratLessard et al. 1988), Samanea saman (Jacq.) Merr. (Satter et al. 1982), Robinia pseudoacacia L. (Moysset \& Simón 1991) e Pterodon pubescens Benth. (Machado \& Rodrigues 2004), espécies com diferentes tipos e velocidades de movimento foliar.

A análise do córtex do pulvino primário das espécies estudadas, com exceção de Zornia diphylla Pers., revelou que o mesmo pode ser dividido de forma semelhante ao proposto para o pulvino secundário de Robinia pseudoacacia por Moysset \& Simón (1991). Nesta espécie, os autores relatam a ocorrência de uma região cortical externa, onde estão as células que apresentam conteúdo fenólico e uma região interna que abrange a endoderme e as camadas corticais adjacentes, que não apresentam conteúdo fenólico.

As células parenquimáticas do córtex externo, denominadas motoras por Toriyama (1953), são consideradas as principais responsáveis pelos movimentos foliares. Suas paredes sinuosas ou dobradas são evidências de modificações no compartimento apoplástico (Fleurat-Lessard 1988, Moysset \& Simón 1991). A ocorrência de espaços intercelulares, como observado nas espécies estudadas, pode facilitar as mudanças na forma e tamanho celular durante a curvatura do pulvino (Fleurat-Lessard \& Millet 1984). A presença de numerosos campos de pontoação nas células motoras indica a existência de intensas trocas simplásticas (Fleurat-Lessard 1988, Fleurat-Lessard \& Millet 1984, Machado \& Rodrigues 2004).

A presença de substâncias fenólicas, particularmente abundantes no córtex de Bauhinia rufa (Bong.) Steud., Copaifera langsdorffii Desf., Dalbergia miscolobium Benth., Mimosa rixosa Mart. e M. flexuosa Mart., confirma a importância dessas substâncias, especialmente os taninos, nos movimentos násticos (Toriyama 1953, 1955, Moysset \& Simón 1991). No pulvino de Zornia diphylla, espécie que exibe somente discretos movimentos heliotrópicos lentos, a coloração com azul de toluidina, bem como o teste com cloreto férrico não detectaram substâncias fenólicas nas células motoras.

Figures 7-14. Pulvinus of legumes from Brazilian "cerrado" transversal sections. 7-9. General view showing uniseriate epidermis, large parenchymatous cortex (ct), central vascular system (vs) and reduced or absent pith. 7. Mimosa rixosa Mart. 8. Mimosa flexuosa Mart. - occurrence of lignified protuberances (arrows) on the pulvinus surface and the dense content (phenolic compounds) of the cortical cells. 9. Stryphnodendron polyphyllum Mart. - calcium oxalate prismatic crystals (arrows) in the cortex. 10. Detail of figure 8 showing lignified protuberance on the surface of the pulvinus and developed vacuome in the outer cortical cells. 11. Bauhinia rufa (Bong.) Steud. - trichomes and uniseriate epidermis constituted by papilous cells with thick cuticle. Epidermal and cortical cells (ct) with phenolic content. 12. Bauhinia rufa showing epidermis (ep) with phenolic content, subepidermal cells in periclinal (arrows) and anticlinal divisions and presence of phenolic compounds and druses (arrow heads) in the cortical cells. 13. Copaifera langsdorffii Desf. - epidermis recovered by thick cuticle (cl), secretor canal (cs) and calcium oxalate prismatic crystals (arrow) in the cortex. 14. Zornia diphylla Pers. - rectangular epidermal cells (ep) recovered by thin cuticle and parenchymatous cortex constituted by voluminous cells with conspicuous nuclei (arrows) and absence of phenolic compounds. Bars $=250 \mu \mathrm{m}(7,9), 160 \mu \mathrm{m}(8), 30 \mu \mathrm{m}(10-11,14), 50 \mu \mathrm{m}(12-13)$. 


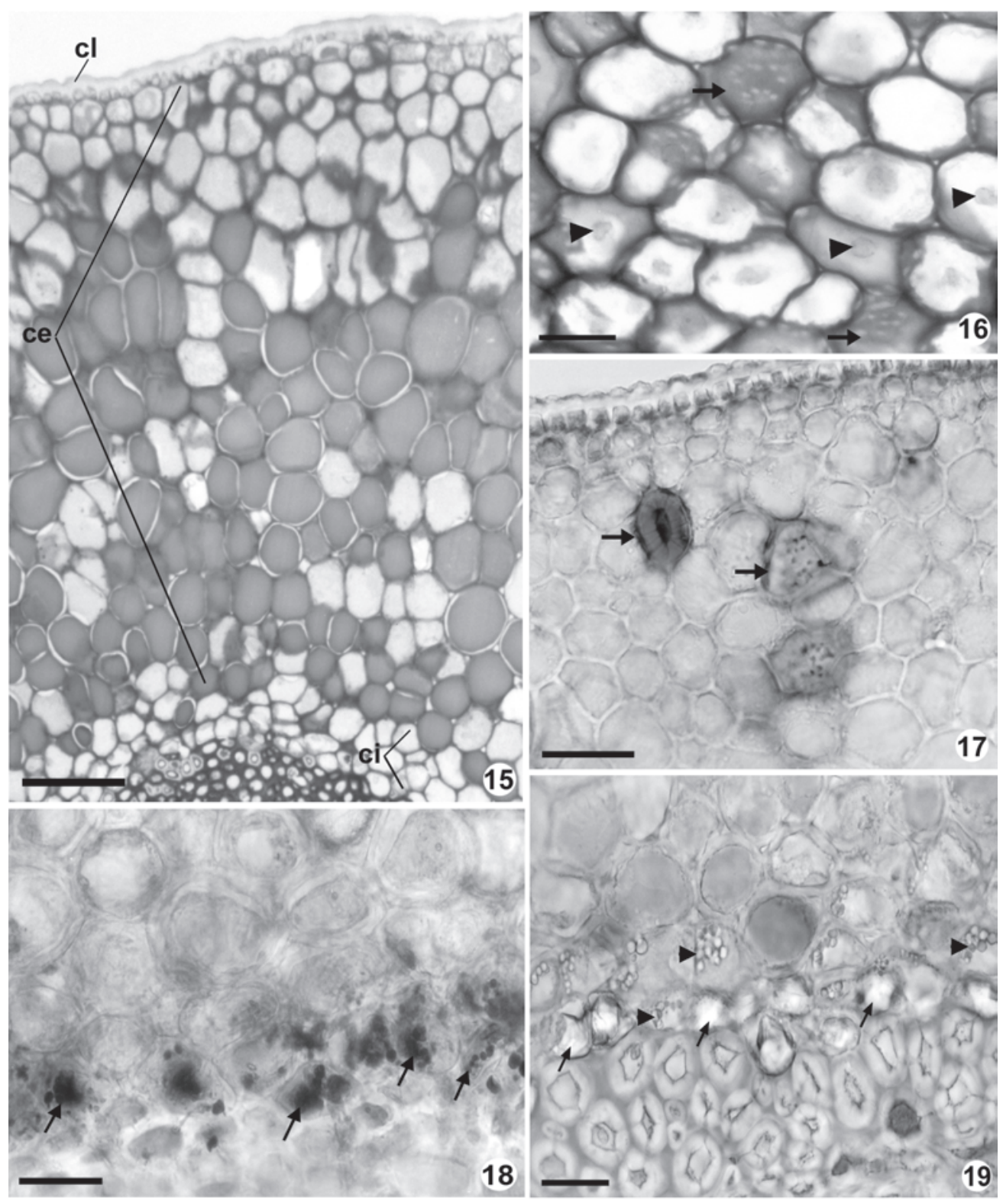

Figuras 15-19. Secções transversais do pulvino de leguminosas do cerrado. 15. Andira humilis Mart. ex Benth. - epiderme unisseriada recoberta por cutícula (cl) espessa e córtex parenquimático amplo, dividido em córtex externo (ce), com células volumosas com conteúdo fenólico, e córtex interno (ci), com células menos volumosas sem conteúdo fenólico. 16. Córtex externo de Zornia diphylla Pers. mostrando células volumosas de paredes sinuosas, com campos de pontoação (setas) e núcleo conspícuo (pontas de seta). 17. Secção de Andira humilis tratada com floroglucina acidificada, mostrando epiderme revestida por cutícula espessa e a presença de esclereides (setas) no córtex externo. 18. Secção tratada com lugol evidenciando presença de grãos de amido (setas) na endoderme de Mimosa rixosa Mart. 19. Bauhinia rufa (Bong.) Steud. mostrando cristais prismáticos de oxalato de cálcio (setas) e grãos de amido (pontas de seta) na endoderme e camadas adjacentes. Barras $=100 \mu \mathrm{m}$ (15), $30 \mu \mathrm{m}(16,18), 50 \mu \mathrm{m}(17), 25 \mu \mathrm{m}(19)$.

Figures 15-19. Pulvinus of legumes from Brazilian "cerrado" transversal sections. 15. Andira humilis Mart. ex Benth. - uniseriate epidermis recovered by thick cuticle $(\mathrm{cl})$ and large parenchymatous cortex divided in outer cortex (ce), with voluminous cells with phenolic content, and inner cortex (ci), with small cells without phenolic content. 16. Outer cortex of Zornia diphylla Pers. showing voluminous cells, with sinuous walls with primary pit fields (arrows) and conspicuous nucleus (arrow heads). 17. Andira humilis pulvinus section treated with acid floroglucin showing epidermis recovered by thick cuticle and the presence of sclereids (arrows) in the outer cortex. 18. Section treated with lugol reagent showing starch grains (arrows) in the endodermis of Mimosa rixosa Mart. 19. Bauhinia rufa showing calcium oxalate prismatic crystals (arrows) and starch grains (arrows heads) in the endodermis and adjacent layers. Bars $=100 \mu \mathrm{m}(15), 30 \mu \mathrm{m}(16,18), 50 \mu \mathrm{m}(17), 25 \mu \mathrm{m}(19)$. 

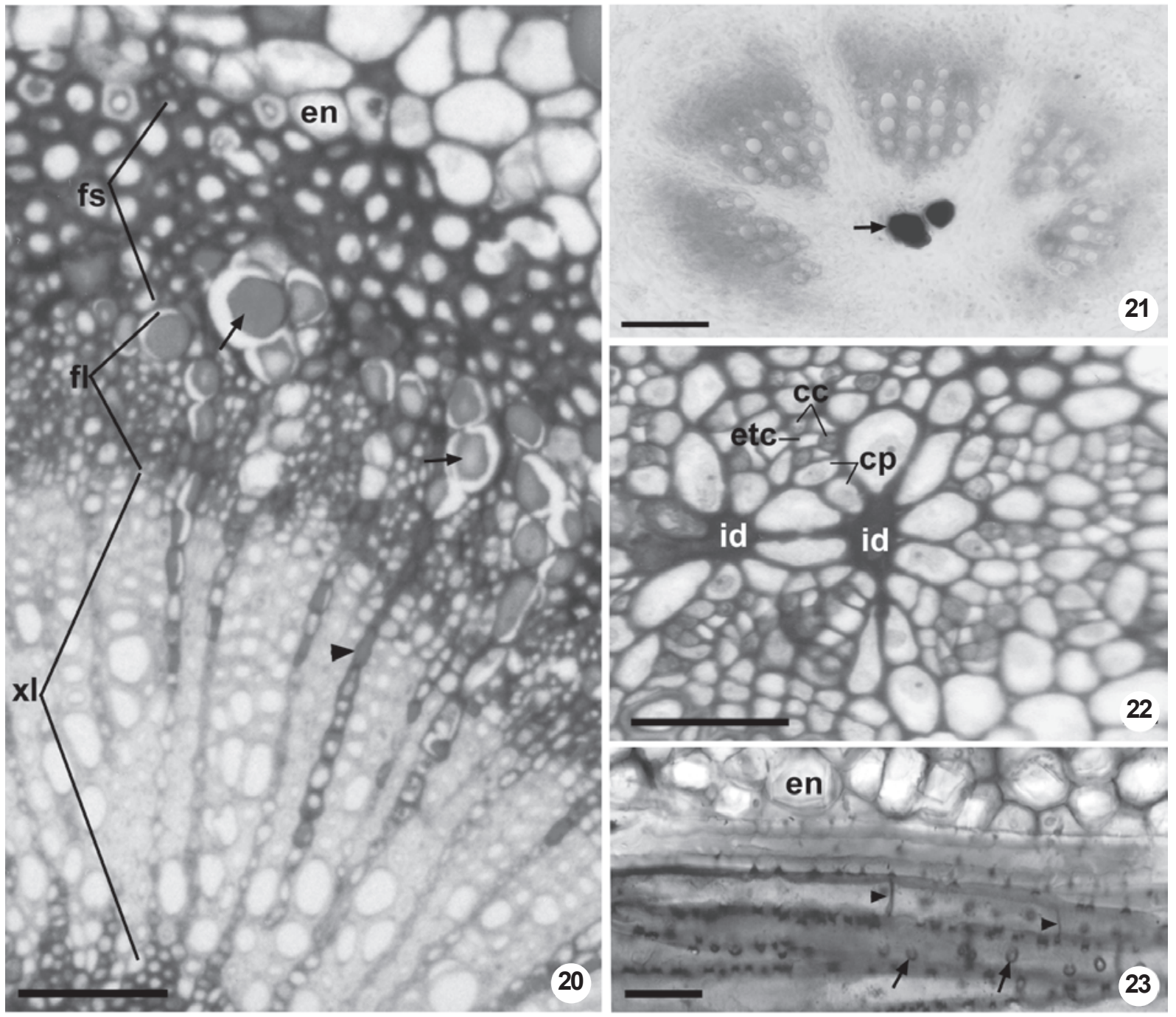

Figuras 20-23. Secções do pulvino de leguminosas do cerrado. 20. Detalhe do pulvino de Andira humilis Mart. ex Benth. - em secção transversal, mostrando endoderme (en), fibras septadas (fs), floema (fl) com idioblastos fenólicos (setas) e xilema (xl) com raios parenquimáticos contendo células repletas de substâncias fenólicas (ponta de seta). 21. Secção transversal do pulvino de Zornia diphylla Pers., mostrando aspecto geral do sistema vascular e presença de idioblastos fenólicos (seta) na medula. 22. Secção transversal mostrando floema de Mimosa flexuosa Mart. com elementos de tubo crivado (etc), células companheiras (cc), células parenquimáticas (cp) e idioblastos (id) mucilaginosos. 23. Secção longitudinal de Andira humilis, mostrando endoderme (en) com cristais de oxalato de cálcio e fibras septadas com campos de pontoação primários (setas) e septos (pontas de seta) evidentes. Barras $=100 \mu \mathrm{m}(20), 50 \mu \mathrm{m}(21), 30 \mu \mathrm{m}(22-23)$.

Figures 20-23. Pulvinus of legumes from Brazilian “cerrado" sections. 20. Detail of Andira humilis Mart. ex Benth. pulvinus in transversal section showing endodermis (en), septate fibers (fs), phloem (fl) with phenolic idioblasts (arrows) and xylem (xl) with parenchymatous rays showing cells with phenolic content (arrow head). 21. Zornia diphylla Pers. pulvinus transversal section showing vascular system general view and phenolic idioblasts (arrow) in the pith. 22. Transversal section showing Mimosa flexuosa Mart. pulvinus phloem where with sieve tube members (etc), companion cells (cc), parenchyma cells (cp) and mucilaginous idioblasts (id). 23. Longitudinal section of Andira humilis pulvinus showing endodermis (en) with calcium oxalate prismatic crystals and septate fibers with thick walls with primary pit fields (arrows) and evident septa (arrow heads). Bars $=100 \mu \mathrm{m}(20), 50 \mu \mathrm{m}(21), 30 \mu \mathrm{m}(22-23)$. 
A ocorrência de vacúolos com conteúdo fenólico nas células epidérmicas do pulvino de Dalbergia miscolobium e das espécies de Caesalpinioideae e Mimosoideae pode estar relacionada com a manutenção da estrutura e integridade de células e tecidos, além da proteção contra a radiação solar elevada (Larcher 2000, Machado \& Rodrigues 2004), condição típica do cerrado. Além disso, substâncias fenólicas podem fornecer proteção contra herbivoria (Langenheim et al. 1982). Toriyama \& Jaffe (1972) observaram mudanças na forma e tamanho dos vacúolos taníferos das células corticais durante o movimento seismonástico em Mimosa pudica. Segundo diversos autores, as substâncias fenólicas, especialmente os taninos, presentes nos vacúolos das células motoras intervêm na estocagem e liberação de íons, especialmente do potássio (Toriyama \& Komada 1971, Campbell et al. 1979, Fleurat-Lessard 1988, Moysset \& Simón 1991) e do cálcio, o qual está envolvido na agregação dos componentes do citoesqueleto, particularmente dos microfilamentos de actina (Fleurat-Lessard \& Millet 1984, Fleurat-Lessard et al. 1988, Kameyama et al. 2000, Yamashiro et al. 2001).

A presença de uma camada cortical interna bem delimitada em todas as espécies analisadas concorda com o relatado por diferentes autores, que a consideram como sendo uma endoderme típica (Fleurat-Lessard 1981, Fleurat-Lessard 1988, Moysset \& Simón 1991). A presença de cristais prismáticos de oxalato de cálcio, além dos grãos de amido, nas células endodérmicas das espécies com movimentos heliotrópico e nictinástico lentos e de somente grãos de amido naquelas com movimentos foliares násticos rápidos confirma a existência de uma relação entre o conteúdo da endoderme e a velocidade do movimento (Morse \& Satter 1979).

A ocorrência de uma bainha de fibras septadas ao redor do floema do pulvino primário das espécies estudadas confirma as observações de Machado \& Rodrigues (2004) para o pulvino primário de Pterodon pubescens. O fato das fibras septadas possuírem paredes pecto-celulósicas com numerosos campos de pontoação é uma evidência morfológica da comunicação simplástica entre o córtex e o cilindro vascular.

A ausência de fibras e esclereides no floema e a presença de elementos fibriformes vivos no xilema, associados à ocorrência de córtex parenquimático amplo nas espécies estudadas são características que asseguram a flexibilidade do pulvino, conforme já relatado em literatura (Fleurat-Lessard \& Bonnemain 1978, Fleurat-Lessard \& Roblin 1982, Moysset \& Simón
1991, Machado \& Rodrigues 2004, Rodrigues \& Machado 2004). A falta de barreiras apoplásticas (lignificação parietal) juntamente com a ocorrência generalizada de campos de pontoação favorece o caminho apoplástico e simplástico, respectivamente, desde a epiderme até o cilindro vascular do pulvino. Tal percurso é fundamental para a rápida redistribuição de íons que se dá durante os movimentos foliares e constitui uma característica diferencial do pulvino em relação a outras regiões da folha (Rodrigues \& Machado 2004).

Em conclusão, pode-se afirmar que existe um padrão geral de organização anatômica comum ao pulvino das diferentes espécies estudadas, independentemente da subfamília a qual pertencem, do porte e do tipo e velocidade do movimento foliar. Contudo, algumas peculiaridades, incluindo a presença e abundância de substâncias fenólicas no córtex externo e o conteúdo das células endodérmicas do pulvino, estão possivelmente relacionadas com o tipo e velocidade do movimento foliar apresentado.

Agradecimentos - À Fapesp, pela concessão de bolsa de mestrado a T. M. Rodrigues (MS 03/11050-7) e apoio financeiro ao desenvolvimento deste trabalho (Programa Biota 00/12469-3), e ao CNPq, pela bolsa de produtividade em pesquisa a S. R. Machado.

\section{Referências bibliográficas}

BUKATSCH, F. 1972. Bemerkungen zur Doppelfärbung Astrablau-Safranin. Mikrokosmos 61:255.

BURGER, L.M. \& RICHTER, H.G. 1991. Anatomia da Madeira. Livraria Nobel, São Paulo.

CALDAS, L.S.L, LÜTTGE, U., FRANCO, A.C. \& HARIDASAN, M. 1997. Leaf heliotropism in Pterodon pubescens, a woody legume from the brazilian cerrado. Revista Brasileira de Fisiologia vegetal 9:1-7.

CAMPBELL, N.A. \& THOMSON, W.W. 1977. Multivacuolate motor cells in Mimosa pudica L. Annals of Botany 41:1361-1362.

CAMPBELL, N.A., STIKA, K.M. \& MORRISON, G.H. 1979. Calcium and potassium in the motor organ of the sensitive plant: localization by ion microscope. Science 204:185-187.

CAMPBELL, N.A. \& GARBER, R.C. 1980. Vacuolar reorganization in motor cells of Albizzia during leaf movement. Planta 148:251-255.

FLEURAT-LESSARD, P. 1981. Ultrastructural features of the starch sheat cells of the primary pulvinus after gravistimulation of the sensitive plant (Mimosa pudica L.). Protoplasma 105:177-184.

FLEURAT-LESSARD, P. 1988. Structural and ultrastructural features of cortical cells in motor organs of sensitive plants. Biological Review 63:1-22. 
FLEURAT-LESSARD, P. \& BONNEMAIN, J.-L. 1978. Structural and ultrastrucutral characteristics of the vascular apparatus of the sensitive plant (Mimosa pudica L.). Protoplasma 94:127-143.

FLEURAT-LESSARD, P. \& ROBLIN, G. 1982. Comparative histocitology of the petiole and the main pulvinus in Mimosa pudica L. Annals of Botany 50:83-92.

FLEURAT-LESSARD, P. \& MILLET, B. 1984. Ultrastructural features of cortical parenchyma cells ("motor cells") instamen of Berberis canadensis Mill. and terciary pulvini of Mimosa pudica L. Journal of Experimental Botany 35:1332-1341.

FLEURAT-LESSARD, P., ROBLIN, G., BONMORT, J. \& BESSE, C. 1988. Effects of colchicine, vinblastine, cytochalasin $\mathrm{B}$ and phalloidin on the seismonastic movement of Mimosa pudica leaf and on motor cell ultrastructure. Journal of Experimental Botany 39:209-221.

GRIGNON, N., TOURAINE, B. \& GRIGNON, C. 1992. Internal phloem in the pulvinus of soybean plants. American Journal of Botany 50:83-92.

JENSEN, W.A. 1962. Botanical histochemistry: principles and practice. W.H. Freeman, San Francisco.

JOHANSEN, D.A. 1940. Plant michrotechnique. McGraw-Hill, New York.

JUDD, W.S., CAMPBELL, C.S., KELLOG, E.A. \& STEVENS, P.F. 1999. Plant Systematics: a phylogenetic approach. Sinauer Associates, Massachusetts.

KAMEYAMA, K., KISHI, Y., YOSHIMURA, M., KANZAWA, N., SAMESHIMA, M. \& TSUCHIYA, T. 2000. Tyrosine phosphorylation in plant bending. Nature 407:37.

KOLATTUKUDY, P.E. 1984. Biochemistry and function of cutin and suberin. Canadian Journal of Botany 62:2918-2933.

KUMMERON, J. \& ALEXANDER, J.V. 1978. Chaparral plants under water stress. Environment southwest 483:3-7.

LANGENHEIM, J.H., LINCOLN, D.E., STUBBLEBINE, W.H. \& GABRIELLI, A.C. 1982. Evolutionary implications of leaf resin pocket patterns in the tropical tree Hymenaea (Caesalpinioideae: Leguminosae). American Journal of Botany 69:595-607.

LARCHER, W. 2000. Ecofisiologia vegetal. RiMa, São Carlos.

MACHADO, S.R. \& RODRIGUES, T.M. 2004. Anatomia e ultra-estrutura do pulvino primário de Pterodon pubescens Benth. (Fabaceae-Faboideae). Revista Brasileira de Botânica 27:135-147.

MENDONÇA, R.C., FELFILI, J.M., WALTER, B.M.T., SILVA, M.C., REZENDE,A.V.,FILGUEIRAS,A.V.\&NOGUEIRA, P.E. 1998. Flora vascular do bioma cerrado. In Cerrado: ambiente e flora (S.M. SANO \& S.P. ALMEIDA, eds.). Embrapa-CPAC, Planaltina.

MORSE, M.J. \& SATTER, R.L. 1979. Relationship between motor cell ultrastructure and leaf movements in Samanea saman. Physiology Plantarum 46:338-346.
MOYSSET, L. \& SIMÓN, E. 1991. Secondary pulvinus of Robinia pseudoacacia (Leguminosae): structural and ultrastructural features. American Journal of Botany 78:1467-1486

O'BRIEN, T.P., FEDER, N. \& MCCULLY, M.E. 1965. Polychromatic staining of plant cell walls by toluidine blue O. Protoplasma 59:368-373.

POLHILL, R.M. 1981. Advances in legume systematics. Royal Botanic Gardens, Kew.

RATTER, J.A., RIBEIRO, J.F. \& BRIDGEWATER, S. 1997. The Brazilian cerrado vegetation and threats to its biodiversity. Annals of Botany 80:223-230.

RODRIGUES, T.M. \& MACHADO, S.R. 2004. Anatomia comparada do pulvino, pecíolo e raque de Pterodon pubescens Benth. (Fabaceae-Faboideae). Acta Botanica Brasilica 18:381-390.

SASS, J.E. 1951. Botanical microtechnique. $2^{\text {nd }}$ ed. Iowa State University Press, Ames.

SATTER, R.L., SABNIS, D.D. \& GALSTON, A.W. 1970. Phytochrome controlled nyctinasty in Albizzia julibrissin. I. Anatomy and fine structure of the pulvinule. American Journal of Botany 57:374-381.

SATTER, R.L., GARBER, R.C., KHAIRALLAH, L. \& CHENG, Y.-S. 1982. Elemental analysis of freeze-dried thin sections of Samanea motor organs: barriers to ion diffusion through the apoplast. The Journal of Cell Biology 95:893-902.

SOUZA, V.C. \& LORENZI, H. 2005. Botânica sistemática: Guia ilustrado para identificação das famílias de Angiospermas da flora brasileira, baseado em APG II. Plantarum, Nova Odessa.

TORIYAMA, H. 1953. Observational and experimental studies of sensitive plants I: The structure of parenchymatous cells of pulvinus. Cytology 18:283-292.

TORIYAMA, H. 1954. Observational and experimental studies of sensitive plants. II. On the changes in motor cells of diurnal and nocturnal condition. Cytologia 19:29-40.

TORIYAMA, H. 1955. Observational and experimental studies of sensitive plants. V. The development of the tannin vacuole in the motor cell of the pulvinus. Botanical Magazine 68:203-208.

TORIYAMA, H. 1957. Observational and experimental studies of sensitive plants. VII. The migration of colloidal substance in the primary pulvinus. Cytologia 22:184-192.

TORIYAMA, H. 1967. A comparison of the Mimosa motor cells before and after stimulation. Proceedings of the Japan Academy 43:541-546.

TORIYAMA, H. \& SATÔ, S. 1968. Electron microscopic observations of the motor cells of Mimosa pudica L. I. A comparision of the motor cells before and after stimulation. Proceedings of the Japan Academy 44:702-706. 
TORIYAMA, H. \& KOMADA, Y. 1971. The recovery process of the tannin vacuole in the motor cell of Mimosa pudica L. Cytologia 36:690-697.

TORIYAMA, H. \& JAFFE, M.J. 1972. Migration of calcium and its role in the regulation of seismonasty in the motor cell of Mimosa pudica L. Plant Physiology 49:72-81.
YAMASHIRO, S., KAMEYAMA, K., KANZAWA, N., TAMIYA, T., MABUCHI, I. \& TSUCHIYA, T. 2001. The gelsolin/fragminfamily protein identified in the higher plant Mimosa pudica. Journal of Biochemistry 130:243-249. 